of the meeting for those without pressing engagements elsewhere.

The commonly pursued subsidiary aims of the ward round are in themselves valuable but can prove unhelpful distractions from the main agenda. They may, in my experience, profitably be structured into a 'doctors' meeting' and a 'staff meeting'. Both of these can be used to increase staff involvement in the running of the ward, as well as being educational and recreational. With the forthcoming introduction of a clinical component to Part 1 of the Membership examination a doctors' meeting could provide an ideal forum for practice in the detailed presentation of cases, as well as other aspects of clinical supervision. I am not suggesting that a doctors' meeting should supplant day to day counsel, but rather add to it.

This proposed format for ward meetings has several potential disadvantages. It replaces one tried, tested and flexible meeting, part of the oral tradition of psychiatric method, with up to three meetings, modestly different in style and content, needing considerable preparation. There is the danger that the 'means' of the meeting will come to dominate the 'ends' and that the introduction of such different practices will be resisted. Effective change is said usually to come from the top. ${ }^{5}$ The consultants I have worked with who run meetings significantly different from the 'average', 2.5 hour, multiple agenda, meeting described above were all of the opinion that rapid regression towards the 'average' would follow withdrawal of their determination and energy.

I would contend that the benefits of such a style outweigh both the risks and extra effort involved. The limiting of numbers of staff, coupled with preplanning and chairing, encourages participation and effective use of time. The consequent brevity allows sustained attention. Optimally, all staff should leave the meeting with established, shared goals and defined areas of accountability. The ward round would thus be central to the co-ordinated planning of patient management, and therefore an essential focus for all members of the team. Finally, setting clear aims for the meeting itself and the use of problem lists would enable clinical audit to be introduced with little additional work.

I calculate that, during the course of a 35 year career in psychiatry, more than 1.5 of these will be spent in ward rounds. From another perspective, casting half an eye towards clinical budgeting, a ward round costs over $£ 200$ per week for manpower alone. To run ward rounds effectively (and enjoyably?) must therefore be in the interests of all.

\section{ACKNOWLEDGEMENT}

I am grateful to all the consultants for the training I have received.

\section{REFERENCES}

${ }^{1}$ Mental Health Act 1983: Section 118-Draft Code of Practice. (1985). London: DHSS.

${ }^{2}$ Editorial (1986) British Journal of Clinical and Social Psychiatry, 4, No. 1.

${ }^{3}$ Wilkinson, G. \& Williams, P. (1986) Development of a scale to measure treatment attitudes in psychiatry. British Journal of Psychiatry, 148, 581-586.

4Parkinson, C. N. (1958) Parkinson's Law. London: John Murray.

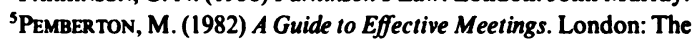
Industrial Society.

\title{
Mental Health Foundation Essay Prize
}

A prize to the value of $£ 500$ will be awarded for an essay during the 1987/88 Session of the Section of Psychiatry of the Royal Society of Medicine. Candidates in the United Kingdom and the Republic of Ireland in training at any grade from senior house officer to senior registrar or equivalent are eligible and need not be members of The Royal Society of Medicine.
Essays must be submitted by 15 April 1988 for consideration this Sessions.

Further details can be obtained from Mrs F. BanrandHebert, Sections Office, The Royal Society of Medicine, 1 Wimpole Street, London WIM 8AE. 